\title{
Specificity analysis of the college humanistic education between United States and China
}

\author{
Li Sheng \\ Inner Mongolia University for the Nationalites 028043 tllis0617@163.com
}

Keywords: humanistic education; Specificity; China; United States;

\begin{abstract}
In recent years, many colleges and universities in developed countries in worldwide are increasing emphasis on humanistic education, especially in Europe countries and US, it has a lot of advanced concepts and advantages for humanistic education. In China, because the limitations of traditional professional education model and the implementation of humanistic education in university, the practical effect of humanistic education is not obvious. This paper analyzes the specificity of the college humanistic education between United States and China, and carefully studies how to learn their advantage from the experience of humanistic education in American universities to make up ours deficiencies.
\end{abstract}

\section{Introduction}

Humanistic education is a common topic of higher education. colleges and universities in different countries present difference and specificity in terms of social background, the type of institution, enrollment targets, teaching content and training objectives and other aspects [1]. In the United States, in the process of development of higher education, when science education has been challenging, humanistic education is quietly rising [2]. The "Return" of humanistic education, is not the exclusion and alternative of science education, but to adapt to the future needs of society for higher education, and to form a pattern that both science and humanities education in the higher education system are all important, so that the development of higher education towards a new stage [3]. In recent years, a number of thought-provoking cases occurred in China's universities, university education exposes current problems of humanistic education. In 1998, China's Ministry of Education issued the "Opinions on Strengthening Students' Cultural Quality Education" and stressed that: "Strengthening the cultural quality of education we have conducted, refers to focus on humanistic quality education" [4]. It is thus clear that strengthening the university's humanistic education has an extremely important role for all-round development of human cultivation, and it has become a hot issue in today's higher education reform and development [5]. This paper analyzes specificity of the college humanistic education between United States and China and carefully studies how to learn their advantage from the experience of humanistic education in American universities from to make up ours deficiencies.

\section{Specificity Comparison of college humanistic education between US and China}

\section{Educational concept and guiding ideology}

The basic of humanistic education is how to cultivate good character, to enable students to become talented all-round development, which American universities have long recognized, the U.S. AAMC (Association of American Universities) once proposed if students wanted to better serve social services, it must make all-round development of themselves, so that the personality is perfect. So humanistic education is an integral part for American college. They think humanities education in the classroom is not only understanding, more of a perception of life, and must use a serious mind to take it as the idea of a lifetime. For the United States colleges and universities, the quality of humanities education, can directly affect the future professional ethics and accomplishment of students. So they think that a good talent must have quality firstly.

Compared with the United States, in 1995, the Chinese Ministry of Education has basically 
designated the fundamental concept of humanistic education about Chinese universities, which is the reflection of the quality and professional ethics, and with leading social science, to grasp a solid natural sciences, but also in the real work the use of the understanding knowledge with ease. So, the basic idea of humanities education in US and China's higher education are consistent. The difference is that the United States is a country to relatively advocate freedom and equality, China is a country with a long history of cultural and moral culture, so in this respect, the relative more attention is to culture virtue.

The background of college humanistic education

Whether in the West or in China, college humanistic education in the historical development have gone a long and tortuous journey, culture different humanities scholars, and form the humanistic style in different periods. Because of the different understanding of natural, social, personality ideal and the human self, it ultimately form their different humanistic education backgrounds in western and China's university.

In US colleges and universities, it is regardless of what kind of talent is, the first to face is major in the humanities, social science in some time. Only after laying this foundation, 2-3 years later, you can systematic master the other expertise. U.S. Secretary of Education, Cavazos in the 1990s discussed six goals of American higher education and clearly pointed out: to ensure that all graduates can write papers with logical clarity and correct grammar, and grasp the history of the world, geography and cultural basic knowledge to ensure that on the country's economic and political life, all the college student have a critical analysis of the phenomenon and the ability to solve practical problems [6].

Modern China's education system affected by severe conditions, from the "save the nation and strengthen the country", "emphasis on science and despising the humanities ", "education serves for the proletarian politics" to " developing the country through science and education ", it has never been the shadow of humanistic education. Especially in recent years the exam-oriented education makes the status of people, values, feelings, dignity widespread extinction. The "survey on the culture and consumer trends of citizen in the world" conducted in 1995 shows that the serious value in Chinese is independent, knowledge and polite. The sense of responsibility, tolerance, and respect for others, to communicate with others are taken low level attention. China's education from high school is divided into arts and sciences, directly resulting in a neglect of humanistic education in the school education, leading ricketiness humanistic education's foundation, so that the college students hidden in the ivory tower appears decline moral, a crisis of faith, confused values and failure

Educational process and teaching methods

In United States' colleges and universities, the humanistic education has been in the overall education of students, among the different stages, the received humanistic education is not the same way. For example, in Harvard University, the received humanistic education of students in preparatory stage is to lay the foundation, for students to comprehensively develop, and develop the good mental. While in the master's and doctorate stage it will effectively together with practice, and discuss a variety of novel ways and means. In many Chinese universities, although the humanistic education is as a compulsory course, the class hour is too few or compressed, the teaching content is single and boring, and it is the conservative pedagogy for the basic instruction limited to classroom. Teaching content and curriculum provision

American humanistic education curriculum and teaching content has relevance, coherence and practicality, and pays attention to make humanities courses interpenetration with other disciplines. According to the data statistics in 1998, in American college curriculum, the proportion of the content of humanities and social sciences is about $20 \%$ in total hours. In the 21 st century, American colleges humanistic education is not inferior to other developed countries, they use the approach to combine social and economic development programs to educate students and adjust according to the circumstances, so keep up the advanced pace of community development. In addition, they systematically divide the theory and practice of the humanities, including literature, history, philosophy, economics, politics, law, aesthetics, art, ethics, etc.

Since the reform and opening up, China's higher education has reformed and innovated. 
Humanistic curriculum got attentions in some famous universities. From the beginning of the end of last century, in order to improve the importance of college humanistic education, the teaching programs and curriculum system is made further planning. The Ministry of Education set up some college cultural quality education bases, gradually opened up humanities education. In comprehensive colleges, for example, the humanistic education curriculum is basically divided into; politics and philosophy class; social and economic class; history and culture class. The average course hour proportion of humanities and social science in domestic institutions is about $8 \%$ in the total hours. In most colleges, Marxist theory and ideological and moral lessons are the center, supplemented by humanistic ethics, psychology, law, economics and natural science related disciplines as well as aesthetics, music appreciation and other elective courses consisting of humanities and social sciences curriculum.

Faculty and material building

American universities are much focused on humanistic quality education, only the excellent reputation professor can act as a lecturer for humanistic education. In addition, retired teachers is another valuable resource. American humanistic education curriculum is very new, not just in the classroom, but a combination of economic and social development, mainly in the national culture, it is defined as a required course, which not only improves the quality of teaching, but also attracts student interest. The essence is better penetrated into student. In Harvard University, humanistic education requires students to be familiar with "Western cultural heritage" and uses it as the core curriculum.

In Chinese college, humanities and social science courses are undertaken by the ideological and political theory course's teacher. For example, in comprehensive colleges, it usually contains philosophy, history, economics, moral, natural dialectics, management, counseling and humanities subject's commitments. Browsing through the use materials in our various institutions, it is easy to find the complete knowledge systems, and materials in every subject, but the life education, values, and worldview are defined in the context of the ideological and political education, humanistic education does not fully reflect the love education and unyielding education, not give the subject of teaching - the students, to inject the rich emotions, cannot correctly understand what is happiness and the world from the college humanistic education classroom.

Education evaluation mechanism and continuing education mechanism

Humanistic education in American Universities is a diversified, it can better and effectively integrate the three parties of social, family and school together. On the evaluation is concerned, a variety of ways but also are used. In addition to use student self-assessment, teacher evaluation, student peer assessment, a very important one is the parent evaluation and social evaluation. This solid foundation is through training and cultivation of professional ethics and lays a good foundation for the future to improve the professional level.

Compared with Chinese domestic universities, the criteria of measuring a talent is performance, ethics and training seem indifferent. The single and conservative judgment is that the lack of education in China today. Only postgraduate or $\mathrm{PhD}$ student in China can continue to receive humanistic education, while other students will no longer accept humanistic education, , which is our greatest shortcoming.

\section{Analysis of Experimental results}

In order to make more accurate analysis of the specificity of humanistic education in United States and China, it is necessary to conduct a simulation experiment. Due to the level of the measure standard of humanistic education is so many, in this experiment, the collected career credit metrics experiment for United States, Chinese colleges and universities' students in 2012 through the Internet questionnaires is chosen. As of May 1, 2012, online questionnaire and paper questionnaires were returned 197 questionnaires, 154 valid questionnaires from it are selected. 


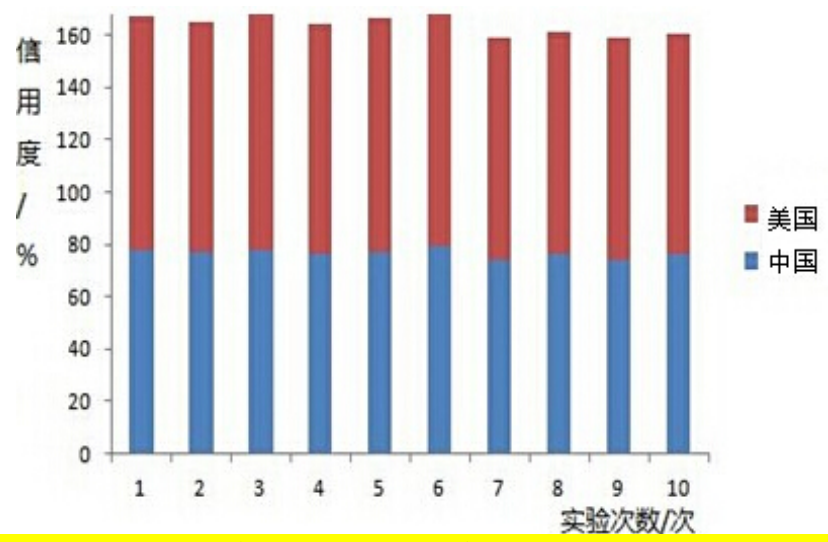

信用度:credit standing ;美国:USA;中国:China; 实验次数/次:the number of experiment/ times

Figure 1 comparison of student's credit undeChina and USA countries' humanistic education

According to the figure can be learned that under the similar outside conditions, the credit of students accepted the humanistic education in the United States, in later career, generally have $10 \%$ higher than students accepted humanistic education in China, fully demonstrating the advantages of American humane education. According to the experiment, it can be sure the advanced humanistic education in United States. Meanwhile, it needs to introduce the advanced philosophy and practice approach of humanistic education in United States' university to China's humanistic education process in order to increase the humanistic education of domestic college students in the shortest time.

\section{Implications for humanistic education in Chinese universities}

\section{Changing concepts of education, adjusting curriculum provision}

Humanistic education curriculum plays an irreplaceable role in the emotional mold, sense of beauty culture, spirit-rich, perfect personality, ideals pursuit, and other spiritual truths exploration cultivation aspects. The first problem faced by education is the idea, the first and most fundament of reconstructing humanistic education is to change the concept of education. Combined with the characteristics of Chinese society, changing the student's personality combines with big development under today's social economy. The humanities courses in favor of students' general cognition are set to allow students easily to absorb, at the same time, through the right amount of electives allows college students to get a modest personality development, in line with the comprehensive development of people's education law. The integration of professional knowledge and humanistic spirit, so as a spirit, a concept which exists throughout the study in order to develop a more detailed professional talent.

Enrich teaching methods and content

Strengthening humanistic education is a gradual process that requires the whole community to give attention. Absorbing American Universities' method of teaching experience, situational teaching, case analysis, etc., for the humanistic education in the context of social background combined with the development of the economic environment, let students to continue to explore and understand with the issue direction, find interest in the question, under the premise of fair and freedom so that students learn to think different issues from different perspectives, improve the ideological and moral awareness in the discussion, understand different perspectives in practice, raise the awareness of professional ethics to lay a solid foundation for the future to become a professional high quality talent in order to better serve the community.

\section{Conclusion}

With the continuous development of society, the humanistic education of developed countries has become increasingly important, and how to better improve the level of humanistic education, to promote the cultivation of all-round science and technology talent, which is an important topic worth to study in Chinese universities. According the description herein, it can be learned, the 
humanistic education in United States requires students to develop their full side to let their personality perfectly. So humanistic education is an integral part in the American college. They think humanities education in the classroom is not only understanding, more of a perception of life, and must use a serious mind to take it as the idea of a lifetime. Humanistic education in Chinese universities is lagging behind, therefore, it needs to introduce the advanced humanistic education of United States to Chinese higher education, so that Chinese students are able to receive the same humanistic education, it will bring the great benefit for the character training and expertise learning of student.

For the United States colleges and universities, the quality of humanities education, can directly affect the future professional ethics and accomplishment of students. So they think that a good talent must have quality firstly.

\section{References}

[1] Wu Bing, Jin Zhongshan. Value function of Humanities courses in medical schools [J]. Chinese medical ethics, 2006 (4):104-106.

[2] Peng Li, Ran Sujuan. Present Situation of Medical Humanities Quality Education in China [J]. Northwest Medical Education, 2009(5):929-931.

[3] Fu Xiaojun, Yin xin. Developing Chinese Quality Education Courses in the Light of Liberal Education in Harvard University [J]. Higher Education of Sciences, 2006 (2):52-56.

[4] Wang Zhijie, Li Zhenxing, Zhang Yue. Research on the Medical Humanity Quality Education in Medical Colleges [J]. Journal of Liaoning Medical university (Social Science Edition), 2007 (1):5-8.

[5] Yuan Li, Qin Bin. International comparison and enlightenment of professional ethics education in medical colleges [J]. Chinese Higher Medical Education, 2004 (1):33-35.

[6] Liu Depei. Medical Humanity Spirit Must be advocated at All Levels [J]. Medicine and Philosophy, 2003 (3):5-6 